\title{
The Prevalence of Psychological Health Impact of COVID-19 Pandemic Among Palestinian Population. A Cross-sectional Study
}

\author{
Nawaf Amro $^{* 1} \quad$ Doaa Abdulhamid ${ }^{2} \quad$ Abed Alkareem Asherah $^{3} \quad$ Rebhi Bsharat $^{1}$ \\ 1. RN, MSN \& CNS. Lecturer, Faculty of Nursing, Modern University College (MUC), Palestine \\ 2. BA \& MSN. Clinical psychology, Al-Ahlyyia Amman University, Jordan \\ 3. RN \& MSN. Lecturer, Applied Science College, Palestine Polytechnic University (PPU), Palestine \\ 4. RN \& PhD. Dean of Modern University College (MUC), Palestine
}

\begin{abstract}
Introduction: The first outbreak was documented in December 2019, in Wuhan, China, as pneumonia of unknown etiology related to a seafood market exposure. According to the Palestinian Ministry of Health, the first cases had been detected at a hotel in the Bethlehem area, where a group of Greek tourists had visited the hotel in late February 2020. There are many previous studies shown that communicable diseases such as Ebola and SARS showed an impact on mental health includes depression, anxiety, and drug abuse. The aims of the study are to assess the prevalence of psychological well-being responses resulted from the COVID-19 pandemic on Palestine general population. Methods: During the middle stage of the outbreak, researchers conducted an online-based survey using a snowballing sample technique. The survey collected data about socio-demographic characteristics and psychological well-being using the general health questionnaire wish consists of (28) questions aimed to assess these sections dealt with somatic symptoms, anguish/anxiety, social dysfunction, and depression. Results: Our survey recruited 1200 subjects of the general public of Palestine. More than two-thirds of subjects were female and their age between 20-39 years. The prevalence of the psychological well-being of the Palestinian subjects. Almost $83 \%$ have poor psychological well-being, while $17 \%$ have good psychological well-being. Significant differences were found in gender $(\mathrm{p}=<0.001)$, marital status $(\mathrm{p}=<0.001)$, place of residence $(\mathrm{p}=<.001)$, types of work ( $\mathrm{p}=.011)$, working status $(\mathrm{p}=<.001)$, a committee to quarantine $(\mathrm{p}=.023)$ and knowing someone who were infected with coronavirus $(\mathrm{p}=<.001)$. Conclusion: Our findings can be used to construct an urgent psychological intervention focused on the general population and to implement public mental health policies in combination with pandemic response efforts in the middle stages of the event.
\end{abstract}

Keywords: Prevalence, General Health, Psychological Health, COVID-19, Pandemic

DOI: $10.7176 / \mathrm{JHMN} / 82-10$

Publication date: November $30^{\text {th }} 2020$

\section{Introduction}

Coronavirus disease 2019 (COVID-19) is a new communicable disease caused by the new strains of severe acute respiratory syndrome coronavirus, SARS-CoV-2 (Wang et al., 2020a). The first outbreak was documented in December 2019, in Wuhan, China, as pneumonia of unknown etiology related to a seafood market exposure (Nishiura et al., 2020). On January 30, the World Health Organization (WHO) declared the outbreak as a Public Health Emergency of International Concern (PHEIC) and a pandemic On March 11 (WHO, 2020).

According to the Palestinian Ministry of Health $(\mathrm{MOH})$, the first cases had been detected at a hotel in the Bethlehem area, where a group of Greek tourists had visited the hotel in late February 2020, with two later diagnosed with the virus (Elbasha, 2020). According to The United Nations Relief and Works Agency (UNRWA), the prolonged blockade imposed has severely impacted the socioeconomic and health conditions of the Occupied Palestinian Territories and Gaza strip (UNRWA, 2019). The longstanding movement restrictions have undermined Gaza's economy and the checkpoints in West Bank to high levels of unemployment, food insecurity, aid dependency, and poor standards of hygiene and sanitation (Alser et al., 2020). Consequently, the government response was swift and immediate, started by launching a social media campaign encouraging people to stay at home and to follow the ministry of health instructions.

The fast climbing of cases of COVID-19 all over the world and the rapid changes in people daily living have left people frightened and alarmed (Alkhamees et al., 2020). Historically, there have been multiple outbreaks over the years, such as the SARS epidemic and swine flu outbreak, a study showed that close to 10 to $30 \%$ of the general population were either very or moderately worried about the possibility of being infected (Lau et al., 2005, Rubin et al., 2010). In addition to that, there are many previous studies shown that communicable diseases such as Ebola and SARS showed an impact on mental health includes depression, anxiety, and drug abuse (Brooks et al., 2020, Al Najjar et al., 2016). In the current pandemic, a study conducted in china concerning COVID-19 psychological impact, revealed that $53.8 \%$ of respondents are showing moderate to severe psychological impact, $16.5 \%$ and $28.8 \%$ reported moderate to high depressive or anxiety symptoms respectively, and $8.1 \%$ moderate to high levels of stress were reported (Wang et al., 2020b).

After deep searching, researchers assumed that no published studies are assessing the general population 
response to the emerging coronavirus infections in Palestine. Therefore, this study aims to assess the prevalence of psychological well-being responses resulted from the COVID-19 pandemic on Palestine general population and the differences between socio-demographic characteristics in terms of psychological well-being total score.

\section{Methods}

\subsection{Study design and setting}

This study followed a cross-sectional design to assess the general population's psychological impact on the COVID19 pandemic at the time of curfew and lockdown in Palestine. Researchers used an online-based questionnaire distributed through social media apps such as Facebook and WhatsApp. The subjects were encouraged to distribute the survey. Subjects have received the survey request through Facebook and WhatsApp's groups of colleagues, family, or friends. These messages showed the study purpose, link, and asked for participation. The survey was titled Psychological Health Impact in Palestine. After clicking on the link of the survey, a cover page showing the study's title, purpose, and needed time for completion showed up. If they agreed to participate, they were asked to click "start the survey," and then they start answering the instrument items.

\subsection{Study procedure and sampling}

As mentioned earlier, the survey was distributed during a period of curfew, and practices of social distancing based on the promoted by the Palestine Ministry of Health $(\mathrm{MOH})$; therefore, we followed an online data collection technique. The survey was done online by using a google survey. All participants were informed about study purposes and provided informed consent. Data were kept confidential and were not disclosed unless for study purposes. Data collected was conducted over one week (April 7-14 April 2020) after cases in Palestine reached more than 1000 subjects. The sample size was calculated using Epi Info ${ }^{\text {TM }} 7$ (Centers for Disease Control and Prevention (CDC), Atlanta, Georgia, USA). The calculated sample size was 1200 based on the assumption of anticipated $\%$ frequency $(\mathrm{p})$ of $50 \%$ of respondents rated the psychological impact of the outbreak as moderate or severe in previous studies, $5 \%$ margin of error, confidence interval (\%) of $95 \%$ and researchers followed a snowball sampling, which is a non-probability sampling method (Wang et al., 2020b).

\subsection{Instrument}

The General Health Questionnaire-28 (GHQ-28) was originally developed in English in London. The questionnaire has been translated into several different languages, including the Arabic language in a primary care setting in Saudi Arabia. Researchers used the validating Arabic Questionnaire to assess subjects' general health during the pandemic of COVID-19 (Alhamad and Al-Faris, 1998). The GHQ consists of (28) questions aimed to assess these sections dealt with somatic symptoms, anguish/anxiety, social dysfunction, and depression.

The scoring system applied in this study was the same as the original scoring system, each item has Four Likert scales ranged from $0=$ Very Bad to 3 Very Good. The minimum score for the GHQ-28 version is 0 , and the maximum is 84 . Higher GHQ-28 scores indicate poor health (Goldberg and Hillier, 1979). Goldberg suggests that subjects with total scores of 23 or below should be classified as good psychological well-being, while subjects with scores $\geq 24$ may be classified as poor psychological well-being (Goldberg et al., 1998). Regarding Reliability, many studies have investigated the reliability of the GHQ-28 in various clinical populations. Test-retest reliability has been reported to be high (0.78 to 00.9$)$ (Robinson and Price, 1982) and interrater and intra-rater reliability have both been shown to be excellent (Cronbach's $\alpha$ 0.9-0.95) (Failde et al., 2000).

\subsection{Pilot study}

A pilot study was conducted at the end of Mar 2020 on (20) subjects who possess the same inclusion criteria of the potential sample. Subjects were understanding the whole instrument, no ambiguous words were mention and the typical time needed to complete the GHQ was 10 minutes.

\subsection{Statistical analysis}

Data were analyzed after scanned the data for the outliers, skewness, and missing value using the IBM Statistical Package of social science program (SPSS) version 26. Descriptive and inferential statistics were used to assess the differences between the dependent and independent variables. Researchers used an Independent t-test and One Way ANOVA to assess if there is a significant difference between the socio-demographic characteristics in terms of psychological well-being.

\subsection{Ethical Consideration}

Ethical approval was obtained from the Modern University College (MUC) to conduct the study. A consent form from the subjects was obtained before started the online-questionnaire. The confidentiality and anonymity of the received data were completely secured by providing code numbers for each subject. 


\section{Results}

Table 1 illustrates the socio-demographic characteristics of the Palestinian subjects. More than two-thirds of subjects were female and their age between 20-39 years. In addition, half of subjects were not work and live in the middle of Palestine. Furthermore, 101 (8.4\%) have been diagnosed with chronic diseases, 97 (8.1\%) have respiratory problems and $78(6.5 \%)$ have history of psychological disorders.

Table 1. Socio-demographic characteristics $(n=1200)$

\begin{tabular}{|c|c|c|c|}
\hline \multicolumn{2}{|c|}{ Demographic characteristics } & $\mathbf{n}$ & $\%$ \\
\hline \multirow{2}{*}{ Gender } & Male & 314 & 26.2 \\
\hline & Female & 886 & 73.8 \\
\hline \multirow{3}{*}{ Age Group } & $<19$ years & 157 & 13.1 \\
\hline & Between 20-39 years & 856 & 71.3 \\
\hline & $>40$ years & 187 & 15.6 \\
\hline \multirow{4}{*}{ Marital Status } & Widow & 247 & 20.6 \\
\hline & Single & 507 & 42.3 \\
\hline & Married & 417 & 34.8 \\
\hline & Divorce & 29 & 2.4 \\
\hline \multirow{3}{*}{ Place of Residence } & South Palestine & 343 & 28.6 \\
\hline & Middle Palestine & 593 & 49.4 \\
\hline & North Palestine & 264 & 22.0 \\
\hline \multirow{5}{*}{ Types of Work } & Governmental sector & 167 & 13.9 \\
\hline & Private sector & 283 & 23.6 \\
\hline & Not Work & 609 & 50.7 \\
\hline & Work in 1948 lands & 54 & 4.5 \\
\hline & Free work & 87 & 7.2 \\
\hline \multirow{2}{*}{ Still Working? } & Yes & 250 & 20.8 \\
\hline & No & 950 & 79.2 \\
\hline \multirow{2}{*}{ Complain of Respiratory Problems? } & Yes & 97 & 8.1 \\
\hline & No & 1103 & 91.9 \\
\hline \multirow{2}{*}{ Complain of Chronic Diseases? } & Yes & 101 & 8.4 \\
\hline & No & 1099 & 91.6 \\
\hline \multirow{2}{*}{ History of Psychological Disorder? } & Yes & 78 & 6.5 \\
\hline & No & 1122 & 93.5 \\
\hline \multirow{2}{*}{ Take any Medication? } & Yes & 211 & 17.6 \\
\hline & No & 989 & 82.4 \\
\hline \multirow{2}{*}{ Knows Someone Infected with Coronavirus? } & Yes & 55 & 4.6 \\
\hline & No & 1145 & 95.4 \\
\hline
\end{tabular}

Table 2 shows the prevalence of psychological well-being of the Palestinian subjects. Almost $83 \%$ have poor psychological well-being, while $17 \%$ have good psychological well-being.

Table 2. Prevalence of Psychological Well-being $(n=1200)$

\begin{tabular}{|l|c|c|}
\hline Prevalence of psychological well-being & n & \% \\
\hline Good Psychological Well-being & 205 & 17.1 \\
\hline Poor Psychological Well-being & 995 & 82.9 \\
\hline
\end{tabular}

Table 3 shows the differences between the socio-demographic characteristics in terms of the total mean score of the psychological well-being. A significant differences were found in gender $(\mathrm{p}=<0.001)$, marital status $(p=<0.001)$, place of resident $(p=<.001)$, types of work $(p=.011)$, working status $(p=<.001)$, committee to quarantine $(\mathrm{p}=.023)$ and knowing someone who were infected with coronavirus $(\mathrm{p}=<.001)$. While, no significant differences were found in age-group $(\mathrm{P}=.083)$, ccomplain of respiratory problems $(\mathrm{P}=.310)$, complain of chronic disease $(\mathrm{P}=.335)$ and the history of psychological disorder $(\mathrm{P}=.288)$.

Regarding gender, male have poorer psychological well-being $(\mathrm{M}=51.63, \mathrm{SD}=19.34)$ than female $(\mathrm{M}=46.78$, $\mathrm{SD}=24.19)$. In addition, subjects who were worked have poorer psychological well-being $(\mathrm{M}=52.76, \mathrm{SD}=18.55)$ than who not worked $(\mathrm{M}=46.81, \mathrm{SD}=24.02)$. More details shown in (Table 3). 
Table 3. Differences Between the Socio-demographic characteristics in terms of Total Sum score of the Psychological Well-being $(\mathrm{n}=1200)$

\begin{tabular}{|c|c|c|c|c|c|c|}
\hline \multicolumn{2}{|c|}{ Demographic characteristics } & n & Mean & SD & $\begin{array}{c}\text { Statistical } \\
\text { Value } \\
\text { (df }\end{array}$ & $\begin{array}{c}\text { P- } \\
\text { value }\end{array}$ \\
\hline \multirow{2}{*}{ Gender } & Male & 314 & 51.63 & 19.34 & \multirow{2}{*}{$\begin{array}{c}t=3.560 \\
(1198)\end{array}$} & \multirow{2}{*}{$<.001$} \\
\hline & Female & 886 & 46.78 & 24.19 & & \\
\hline \multirow{3}{*}{ Age Group } & $<19$ years & 157 & 49.34 & 19.99 & \multirow{3}{*}{$\begin{aligned} \mathrm{F}= & 2.492 \\
& (2)\end{aligned}$} & \multirow{3}{*}{.083 } \\
\hline & $\begin{array}{ll}\text { Between } & 20-39 \\
\text { years }\end{array}$ & 856 & 47.15 & 23.73 & & \\
\hline & $>40$ years & 187 & 51.07 & 22.44 & & \\
\hline \multirow{4}{*}{ Marital Status } & Widow & 247 & 57.10 & 10.31 & \multirow{4}{*}{$\begin{aligned} F= & 17.465 \\
& (3)\end{aligned}$} & \multirow{4}{*}{$<.001$} \\
\hline & Single & 507 & 46.80 & 24.08 & & \\
\hline & Married & 417 & 44.32 & 25.89 & & \\
\hline & Divorce & 29 & 46.48 & 23.06 & & \\
\hline \multirow{3}{*}{ Place of Residence } & South Palestine & 343 & 50.94 & 20.00 & \multirow{3}{*}{$\begin{array}{c}\mathrm{F}=8.013 \\
(2)\end{array}$} & \multirow{3}{*}{$<.001$} \\
\hline & Middle Palestine & 593 & 48.41 & 23.21 & & \\
\hline & North Palestine & 264 & 43.48 & 25.86 & & \\
\hline \multirow{5}{*}{ Types of Work } & $\begin{array}{l}\text { Governmental } \\
\text { sector }\end{array}$ & 167 & 51.88 & 20.90 & \multirow{5}{*}{$\begin{array}{c}\mathrm{F}=3.306 \\
(4)\end{array}$} & \multirow{5}{*}{.011} \\
\hline & Private sector & 283 & 50.09 & 22.40 & & \\
\hline & Not Work & 609 & 46.12 & 23.61 & & \\
\hline & $\begin{array}{l}\text { Work in } 1948 \\
\text { lands }\end{array}$ & 54 & 44.16 & 26.70 & & \\
\hline & Free work & 87 & 49.95 & 22.24 & & \\
\hline \multirow{2}{*}{ Working Status } & Yes & 250 & 52.76 & 18.55 & \multirow{2}{*}{$\begin{array}{c}\mathrm{t}=4.227 \\
(1198)\end{array}$} & \multirow{2}{*}{$<.001$} \\
\hline & No & 950 & 46.81 & 24.02 & & \\
\hline \multirow{2}{*}{$\begin{array}{l}\text { Complain of } \quad \text { Respiratory } \\
\text { Problems }\end{array}$} & Yes & 97 & 45.95 & 20.90 & \multirow{2}{*}{$\begin{array}{l}\mathrm{t}=-.931 \\
(1198)\end{array}$} & \multirow[b]{2}{*}{.310} \\
\hline & No & 1103 & 48.23 & 23.29 & & \\
\hline \multirow[t]{2}{*}{ Complain of Chronic Diseases } & Yes & 101 & 45.88 & 23.63 & \multirow{2}{*}{$\begin{array}{l}\mathrm{t}=-.987 \\
(1198)\end{array}$} & \multirow{2}{*}{.335} \\
\hline & No & 1099 & 48.25 & 23.06 & & \\
\hline \multirow[t]{2}{*}{ History of Psychological Disorder } & Yes & 78 & 46.11 & 15.97 & \multirow{2}{*}{$\begin{array}{c}\mathrm{t}=-1.068 \\
(1198)\end{array}$} & \multirow{2}{*}{.288} \\
\hline & No & 1122 & 48.18 & 23.52 & & \\
\hline \multirow[b]{2}{*}{ Take any Medication } & Yes & 211 & 45.59 & 22.35 & \multirow{2}{*}{$\begin{array}{c}t=-1.706 \\
(1198)\end{array}$} & \multirow[b]{2}{*}{.081} \\
\hline & No & 989 & 48.57 & 23.24 & & \\
\hline Knows Someone Infected & Yes & 55 & 35.03 & 28.60 & $\mathrm{t}=-3.485$ & $<001$ \\
\hline Coronavirus & No & 1145 & 48.67 & 22.64 & (1198) & $<.001$ \\
\hline
\end{tabular}

Independent $t$ test and One Way ANOVA; $\mathrm{SD}=$ Standard Deviation; $\mathrm{DF}=$ Degree of Freedom

\section{Discussion}

The spread of the pandemic and its rapid spread across the world led to a significant deterioration in public health and mental well-being and its negative impact on individuals and societies (Banerjee, 2020, Alkhamees et al., 2020, Panchal et al., 2020).

Regarding the prevalence of the psychological well-being, a study found higher prevalence of poor psychological wellbeing among the Palestinian population. There is a study in harmony with the findings conducted in the United State (US) reported more than half of subject's mental health has been negatively impacted due to worry and stress over the coronavirus (Panchal et al., 2020). Another study conducted in Saudi Arabia shown more than half of subjects have moderate to severe psychological impact regarding COVID-19 (Alkhamees et al., 2020). Consequently, stressful events and traumatic experiences of COVID-19 may predisposed individuals to mood and anxiety disorders; Which affects public health, including physical, psychological and mental. Health depends on social, economic, medical, educational, and employment policies, and it is reasonable that any shift in these determinants will be reflected in the well-being of society and its members (Godinic et al., 2020).

Regarding the differences between socio-demographic characteristics in terms of psychological well-being. The study found that females had significantly poor psychological well-being than males, there is a study in harmony with finding conducted in China shown that females have more psychological problems than male (Wang et al., 2020b). Furthermore, the study showed people who have a job is significantly decrease in psychological 
well-being compared with subjects who did not have a job. The reason it could be because of the increased risk of loss of the job. Previous researches and reports were shown that the COVID-19 pandemic has led to millions of job losses across the country, and the U.S. officially entered an economic recession in February 2020 (Horsley, 2020). The Bureau of Labor Statistics (BLS) in the US reported that the unemployment rate in July decreased from $14.7 \%$ to $10.2 \%$ in April (BLS, 2020). In addition to that, job gains have slowed (Morath, 2020). Research also shows that job loss is associated with poor psychological well-being (Khazan, 2020).

The study found no significant differences between the history of psychological disorders in terms of psychological well-being. There is a study in contrast with the findings, which show people with mental disorders are also more susceptible to stress compared to the general public, and such outbreaks can provoke relapses or even worsen the already existing psychological disorder (Yao et al., 2020).

\section{Conclusion}

Throughout the middle-stage COVID-19 pandemic in Palestine, the results showed that more than two-thirds of the general population experienced poor psychological well-being. Our findings can be used to construct an urgent psychological intervention focused on the general population and to implement public mental health policies in combination with pandemic response efforts in the middle stages of the event.

\section{Limitation}

This study inherent limitation that must be taken into consideration. Convenience sample may limit the generalizability of the results. Researchers recommended using other methods to evaluate the psychological wellbeing.

\section{Acknowledgments}

Authors would like to thank those subjects who took part in this study. No financial or material support were assigned or granted for this study.

\section{Authors' Contribution}

Authors were involved actively in planning and supervised the work of the study. All listed researchers collectively performed the analysis, drafted the manuscript and designed the tables. Researchers interpreted the results and worked on the manuscript. All authors discussed the results and they assigned the first researcher to be correspondent author.

\section{Conflict of Interest}

The authors declare that they have no conflict of interests.

\section{References}

AL NAJJAR, N., ATTAR, L., FARAHAT, F. \& AL THAQAFI, A. 2016. Psychobehavioural responses to the 2014 Middle East respiratory syndrome-novel corona virus [MERS CoV] among adults in two shopping malls in Jeddah, western Saudi Arabia. EMHJ-Eastern Mediterranean Health Journal, 22, 817-823.

ALHAMAD, A. \& AL-FARIS, E. A. 1998. The validation of the general health questionnaire (GHQ-28) in a primary care setting in Saudi Arabia. Journal of family \& community medicine, 5, 13.

ALKHAMEES, A. A., ALRASHED, S. A., AlZUNAYDI, A. A., ALMOHIMEED, A. S. \& ALJOHANI, M. S. 2020. The psychological impact of COVID-19 pandemic on the general population of Saudi Arabia. Comprehensive psychiatry, 102, 152192.

ALSER, O., ALWAHEIDI, S., ELESSI, K. \& MEGHARI, H. 2020. COVID-19 in Gaza: a pandemic spreading in a place already under protracted lockdown. Eastern Mediterranean Health Journal, 26, 762-763.

BANERJEE, D. 2020. The Impact of Covid - 19 Pandemic on Elderly Mental Health. International Journal of Geriatric Psychiatry.

BLS. 2020. THE EMPLOYMENT SITUATION [Online]. Bureau of Labor Statistics. Available: https://www.bls.gov/news.release/pdf/empsit.pdf [Accessed].

BROOKS, S. K., WEBSTER, R. K., SMITH, L. E., WOODLAND, L., WESSELY, S., GREENBERG, N. \& RUBIN, G. J. 2020. The psychological impact of quarantine and how to reduce it: rapid review of the evidence. The Lancet.

ELBASHA, M. 2020. Palestinians confirm 7 coronavirus cases, declare tourist ban [Online]. Available: https://www.timesofisrael.com/palestinians-confirm-7-coronavirus-cases-declare-tourist-ban/ [Accessed].

FAILDE, I., RAMOS, I. \& FERNANDEZ-PALACIN, F. 2000. Comparison between the GHQ-28 and SF-36 (MH 1-5) for the assessment of the mental health in patients with ischaemic heart disease. European journal of epidemiology, 16, 311-316.

GODINIC, D., OBRENOVIC, B. \& KHUDAYKULOV, A. 2020. Effects of Economic Uncertainty on Mental 
Health in the COVID-19 Pandemic Context: Social Identity Disturbance, Job Uncertainty and Psychological Well-Being Model. International Journal of Management Science and Business Administration, 6, 61-74.

GOLDBERG, D., OLDEHINKEL, T. \& ORMEL, J. 1998. Why GHQ threshold varies from one place to another. Psychological medicine, 28, 915-921.

GOLDBERG, D. P. \& HILLIER, V. F. 1979. A scaled version of the General Health Questionnaire. Psychological medicine, 9, 139-145.

HORSLEY, S. 2020. It's Official: U.S. Economy Is In A Recession [Online]. National Public Radio. Available: https://www.npr.org/sections/coronavirus-live-updates/2020/06/08/872336272/its-official-scorekeeperssay-u-s-economy-is-in-a-recession [Accessed].

KHAZAN, O. 2020. How Job Loss Can Lead to Drug Use [Online]. The Atlantic. Available: https://www.theatlantic.com/health/archive/2017/07/how-job-loss-can-lead-to-drug-use/534087/ [Accessed].

LAU, J. T., YANG, X., PANG, E., TSUI, H., WONG, E. \& WING, Y. K. 2005. SARS-related perceptions in Hong Kong. Emerging infectious diseases, 11, 417.

MORATH, E. 2020. U.S. Jobless Claims Rose to 1.1 Million in Latest Week [Online]. The wall street journal. Available: https:/www.wsj.com/articles/unemployment-benefits-jobless-claims-08-20-2020-11597873460 [Accessed].

NISHIURA, H., JUNG, S.-M., LINTON, N. M., KINOSHITA, R., YANG, Y., HAYASHI, K., KOBAYASHI, T., YUAN, B. \& AKHMETZHANOV, A. R. 2020. The extent of transmission of novel coronavirus in Wuhan, China, 2020. Multidisciplinary Digital Publishing Institute.

PANCHAL, N., KAMAL, R., ORGERA, K., COX, C., GARFIELD, R., HAMEL, L. \& CHIDAMBARAM, P. 2020. The implications of COVID-19 for mental health and substance use. Retrieved May, 5, 2020.

ROBINSON, R. G. \& PRICE, T. R. 1982. Post-stroke depressive disorders: a follow-up study of 103 patients. Stroke, 13, 635-641.

RUBIN, G. J., POTTS, H. \& MICHIE, S. 2010. The impact of communications about swine flu (influenza A H1N1v) on public responses to the outbreak: results from 36 national telephone surveys in the UK. Health Technology Assessment, 14, 183-266.

UNRWA. 2019. WHERE WE WORK [Online]. Available: https://www.unrwa.org/where-we-work/gaza-strip [Accessed].

WANG, C., HORBY, P. W., HAYDEN, F. G. \& GAO, G. F. 2020a. A novel coronavirus outbreak of global health concern. The Lancet, 395, 470-473.

WANG, C., PAN, R., WAN, X., TAN, Y., XU, L., HO, C. S. \& HO, R. C. 2020b. Immediate psychological responses and associated factors during the initial stage of the 2019 coronavirus disease (COVID-19) epidemic among the general population in China. International journal of environmental research and public health, 17, 1729.

WHO. 2020. Coronavirus disease (COVID-19) Weekly Epidemiological Update and Weekly Operational Update [Online]. Available: https://www.who.int/emergencies/diseases/novel-coronavirus-2019/situation-reports [Accessed].

YAO, H., CHEN, J.-H. \& XU, Y.-F. 2020. Patients with mental health disorders in the COVID-19 epidemic. The Lancet Psychiatry, 7, e21. 